\title{
Evaluation of Visceral and Subcutaneous Fat by Ultrasound and Its Relationship with Clinical and Metabolic Parameters of Insulin Resistance and Subclinical Atherosclerosis
}

\author{
Clarisse Miranda Prado, Germana Augusto de Vasconcelos, Emmanuelle Tenorio A. M. Godoi, \\ Érica Nogueira Bezerra Cavalcanti, Tiago Matos de Arruda, Erik Trovão Diniz, \\ Cynthia Salgado Lucena, Luiz Griz, Francisco Bandeira \\ Hospital Agamenon Magalhães, SUS/Universidade de Pernambuco, Recife, Brasil \\ Email: fbone@hotlink.com.br
}

Received September 1, 2012; revised October 3, 2012; accepted November 5, 2012

\begin{abstract}
Objective: this study set out to investigate the association between abdominal obesity ultrasound measurements, waist circumference and body mass index (BMI), metabolic syndrome (MS) components and subclinical atherosclerosis. Methods: sixty patients were recruited and divided equally into two groups, according to the presence of MS. All subjects had an ultrasound examination for measurement of visceral and subcutaneous fat thickness and carotid IMT. Results: the values of visceral fat thickness, preperitoneal circumference and carotid IMT were higher in patients with MS than in control subjects. Visceral fat thickness showed significant correlations with many cardiovascular risk factors (waist circumference, BMI, fasting plasma glucose, HDL and LDL cholesterol). All abdominal obesity measurements were correlated with BMI. Carotid IMT showed correlations with age, visceral fat and preperitoneal circumference. Visceral fat was independently associated with systolic and diastolic blood pressures and fasting plasma glucose. Systolic and diastolic blood pressures and BMI were independent determinants of carotid IMT. Conclusion: visceral fat thickness showed the best correlation with MS components, suggesting that it could be a useful parameter in cardiovascular risk assessment. Age, systolic and diastolic blood pressures and BMI were independent determinants of subclinical atherosclerosis. MS was associated with a higher carotid IMT.
\end{abstract}

Keywords: Visceral Fat Thickness; Subcutaneous Fat Thickness; Preperitoneal Circumference; Carotid Intima-Media Thickness; Metabolic Syndrome

\section{Introduction}

A strong association has been shown between the metabolic syndrome (MS) and an increased risk of cardiovascular and total mortality [1-4]. Individuals with MS have a higher risk of stroke and coronary artery disease $[5,6]$.

The carotid intima-media thickness (IMT) is an established indicator of atherosclerosis and is used as a surrogate marker for cardiovascular morbidity and mortality [7-10]. Recent studies have shown an association between MS and increased carotid IMT [11,12].

Although obesity is recognized as an important risk factor for cardiovascular disease (CVD) [13], the greatest challenge is to identify measurements of obesity that best reflect an increased risk of developing MS [14]. Abdominal fat, represented by subcutaneous and visceral adipose tissue, has been associated with MS $[15,16]$. However, there is still controversy as to whether these measurements provide additional information on the complications of MS [17].

This study aimed to investigate the association between abdominal obesity ultrasound measurements, waist circumference and body mass index (BMI), on the one hand, and MS components and subclinical atherosclerosis, on the other.

Some components, such as multi-leveled equations, graphics, and tables are not prescribed, although the various table text styles are provided. The formatter will need to create these components, incorporating the applicable criteria that follow.

\section{Methods}

This was a cross-sectional study, which involved 60 patients treated on an outpatient basis at Agamenon Magalhães Hospital, Recife, from March to July 2008. 
The inclusion criterion was age between 20 and 80 years and the exclusion criteria were use of antiretroviral drugs, chronic use of glucocorticoids and pregnancy. The study was approved by the hospital's Ethics Committee, and all patients gave their written consent. Patient identification data, medication use, disease history and results of laboratory tests performed less than a month prior to the interview, as well as measurements of the patients' blood pressure, waist circumference, weight, height and BMI were recorded. Blood pressure was measured in the right and left arms using the mercury sphygmomanometer with the patient seated after 5 minutes' rest. Patients who had smoked at least one cigarette per day during the previous six months were considered smokers.

A. Laboratory tests: a venous blood sample was collected after a fast of at least 12 hours to measure fasting blood glucose and serum lipids. The results were obtained by the dry-slide method, using the Vitros 950 Chemistry System (Ortho-Clinical Diagnostics, Johnson \& Johnson Company).

B. Ultrasound measurements: the equipment used was a Philips En Visor C (Bothell, USA). The abdominal ultrasound was performed by two specialists, but all measurements of carotid IMT were performed by a single operator and those of intra-abdominal fat by another. Neither operator had any information on the patients' clinical and laboratory data.

The measurement of carotid IMT was performed with the patient in the supine position, using a 5.0 to 10.0 $\mathrm{MHz}$ linear array transducer. Three IMT measurements were made in the plaque-free section of both the right and left common carotid arteries, along the thickest point on the far wall and within $\sim 1.5 \mathrm{~cm}$ proximal to the flow divider. The sonographic vascular lumen-intima transition was selected as the internal measurement site and the media-adventitia transition as the external one. An average of six measurements was used for the other calculations $[16,18]$.

The measurement of visceral and subcutaneous fat was performed with a 2.0 to $5.0 \mathrm{MHz}$ linear array transducer along the midline of the abdomen, between the xiphoid process and the umbilicus. The subcutaneous fat was measured between the skin-fat interface (excluding the skin) and the outer surface of the abdominal rectus muscle. The visceral fat was measured between the inner face of the rectus muscle and the posterior wall of the abdominal aorta [19]. The two measurements were repeated three times, following which the mean of the measurements was calculated for each type of fat. The preperitoneal circumference was calculated using the formula: $\mathrm{PC}=\mathrm{AC}-(2 \pi \times \mathrm{SCF}) / \mathrm{PC}=$ preperitoneal circumference $/ \mathrm{AC}=$ abdominal circumference $/ \mathrm{SCF}=$ subcutaneous fat [20].

Definition of SM: We used the revised definition of the National Cholesterol Education Program (NCEP) and Adult Treatment Panel III (ATP III) [21]. The diagnosis of MS was made in the presence of at least three of the following five criteria: 1 ) waist circumference: $\geq 102 \mathrm{~cm}$ in men and $\geq 88 \mathrm{~cm}$ in women; 2) triglycerides $\geq 150$ $\mathrm{mg} / \mathrm{dl}$ or patients using fibrates or nicotinic acid; 3) $\mathrm{HDL}<40$ $\mathrm{mg} / \mathrm{dl}$ in men and $<50 \mathrm{mg} / \mathrm{dl}$ in women or patients using fibrates or nicotinic acid; 4) systolic blood pressure $\geq 130$ $\mathrm{mmHg}$ or diastolic blood pressure $\geq 85 \mathrm{mmHg}$ or patients using an antihypertensive drug; and 5) fasting plasma glucose $\geq 100 \mathrm{mg} / \mathrm{dl}$ or use of hypoglycemic medication.

Statistical analysis: Continuous variables were expressed as mean and standard deviation and categorical variables as percentages. The Student t-test was used to compare groups of continuous variables and the chisquare test for proportions. Pearson's correlation was used to examine the associations between the ultrasound measurements themselves and between these and the epidemiological and metabolic parameters. Multiple regression was used to establish the independent contribution of the ultrasound to each component of MS. The same procedure was also used to identify independent determinants of carotid IMT, using the latter as a dependent variable. All tests were performed using the program SPSS (Statistical Package for the Social Sciences) for Windows, version 13 P-values $<0.05$ were considered statistically significant.

\section{Results}

The characteristics of the subjects are shown in Table 1. Sixty patients, of whom 48 were females and 28 had a diagnosis of diabetes mellitus (DM), were evaluated. The 60 participants were divided equally into two groups, according to the presence or absence of MS. The group of MS patients, when compared with the group without MS, had a higher mean age, higher values for waist circumference, BMI, fasting plasma glucose and triglycerides, and lower levels of HDL cholesterol. The use of antihypertensive and hypoglycemic drugs and statins was also higher among the patients with MS. Visceral fat, preperitoneal circumference and carotid IMT were significantly higher in the MS patients. The subcutaneous fat showed no significant differences between groups.

Table 2 shows that, among the measurements of abdominal fat, visceral fat showed a higher positive correlation with cardiovascular risk factors, presenting an association with BMI, waist circumference, fasting plasma glucose, HDL and LDL cholesterol. The subcutaneous fat was correlated with BMI and waist circumference. The preperitoneal circumference was related to BMI, waist circumference and HDL cholesterol. Waist circumference was correlated with fasting plasma glucose and BMI. Thus, all measurements of central obesity 
Table 1. Clinical and laboratory characteristics of the population according to presence or absence of MS.

\begin{tabular}{|c|c|c|c|}
\hline \multirow{3}{*}{ Variables } & \multicolumn{2}{|c|}{ Group } & \multirow{3}{*}{$\mathrm{p}$-value } \\
\hline & With metabolic syndrome & Without metabolic syndrome & \\
\hline & Mean \pm standard deviation & Mean \pm standard deviation & \\
\hline - Age (years) & $54.1 \pm 11.02$ & $46.4 \pm 14.03$ & $\mathrm{p}^{(1)}=0.026^{*}$ \\
\hline - Female, N (\%) & $23(76.7 \%)^{* *}$ & $25(83.3 \%)^{* *}$ & $\mathrm{p}^{(2)}=0.519$ \\
\hline - Smoking, N (\%) (current/ex) & $10(33.3 \%)$ & $5(16.7 \%)$ & $\mathrm{p}^{(2)}=0.136$ \\
\hline - Waist circumference $(\mathrm{cm})$ & $98.6 \pm 11.73$ & $88.7 \pm 12.77$ & $\mathrm{p}^{(3)}=0.003^{*}$ \\
\hline - BMI $\left(\mathrm{Kg} / \mathrm{m}^{2}\right)$ & $28.9 \pm 4.19$ & $25.7 \pm 5.08$ & $\mathrm{p}^{(3)}=0.009^{*}$ \\
\hline - Systolic blood pressure (mmHg) & $132.8 \pm 20.79$ & $123.5 \pm 15.76$ & $\mathrm{p}^{(1)}=0.055$ \\
\hline - Diastolic blood pressure (mmHg) & $81.2 \pm 12.84$ & $78.7 \pm 10.17$ & $\mathrm{p}^{(1)}=0.407$ \\
\hline - Use of antihypertensive, $\mathrm{N}(\%)$ & $27(90.0 \%)$ & $11(36.7 \%)$ & $\mathrm{p}^{(2)}<0.001^{*}$ \\
\hline - Fasting plasma glucose (mg/dl) & $133.6 \pm 66.08$ & $99.2 \pm 42.18$ & $\mathrm{p}^{(1)}=0.022^{*}$ \\
\hline - Use of hypoglycemic, N (\%) & $19(63.3 \%)$ & $6(20.0 \%)$ & $\mathrm{p}^{(2)}=0.001^{*}$ \\
\hline - Total cholesterol (mg/dl) & $183.7 \pm 47.16$ & $196.8 \pm 42.70$ & $\mathrm{P}^{(3)}=0.264$ \\
\hline - HDL cholesterol (mg/dl) & $39.3 \pm 10.65$ & $56.9 \pm 14.56$ & $\mathrm{p}^{(3)}<0.001^{*}$ \\
\hline - Triglycerides (mg/dl) & $264.6 \pm 371.70$ & $103.7 \pm 47.46$ & $\mathrm{p}^{(1)}=0.025^{*}$ \\
\hline - LDL cholesterol (mg/dl) & $106.0 \pm 35.81$ & $119.1 \pm 39.24$ & $\mathrm{p}^{(3)}=0.189$ \\
\hline - VLDL cholesterol (mg/dl) & $43.0 \pm 62.87$ & $20.8 \pm 9.45$ & $\mathrm{p}^{(3)}=0.061$ \\
\hline - Use of statin, N (\%) & $13(43.3 \%)$ & $5(16.7 \%)$ & $\mathrm{p}^{(2)}=0.024^{*}$ \\
\hline - Visceral fat (cm) & $5.38 \pm 1.89$ & $4.44 \pm 1.47$ & $\mathrm{p}^{(1)}=0.035^{*}$ \\
\hline - Subcutaneous fat (cm) & $2.16 \pm 0.97$ & $2.20 \pm 2.12$ & $\mathrm{p}^{(1)}=0.925$ \\
\hline - Preperitoneal circumference (cm) & $85.03 \pm 8.15$ & $74.91 \pm 12.41$ & $\mathrm{p}^{(1)}<0.001^{*}$ \\
\hline - Carotid intima-media thickness (mm) & $0.69 \pm 0.14$ & $0.58 \pm 0.12$ & $\mathrm{p}^{(1)}=0.001^{*}$ \\
\hline
\end{tabular}

"Significant difference at $5.0 \% ;{ }^{* *}$ The percentages were based on 30 patients in each group; ${ }^{(1)}$ Using the student $\mathrm{t}$-test with equal variances; ${ }^{(2)}$ Using the pearson chi-square test; ${ }^{(3)}$ Using the student t-test with unequal variances.

Table 2. Pearson's correlation coefficients significantly different from zero between ultrasound measures and several selected variables (metabolic syndrome group).

\begin{tabular}{|c|c|c|c|c|c|}
\hline & Waist circumference & $\begin{array}{l}\text { Preperitoneal } \\
\text { circumference }\end{array}$ & Visceral fat & Subcutaneous fat & Carotid IMT \\
\hline - Age & Ns & Ns & $\mathrm{ns}$ & ns & $0.499(<0.001)$ \\
\hline - $\mathrm{BMI}^{*}$ & $0.830(<0.001)$ & $0.573(<0.001)$ & $0.474(<0.001)$ & $0.414\left(0.001^{*}\right)$ & ns \\
\hline - Waist circumference & --------- & $0.661(<0.001)$ & $0.615(<0.001)$ & $0.533(<0.001)$ & ns \\
\hline - $\mathrm{FPG}^{*}(\mathrm{mg} / \mathrm{dl})$ & $0.263(0.044)$ & Ns & $0.325(0.012)$ & ns & ns \\
\hline - HDL & Ns & $-0.449(<0.001)$ & $-0.262(0.043)$ & ns & ns \\
\hline - LDL & Ns & Ns & $0.296(0.024)$ & ns & $\mathrm{ns}$ \\
\hline - Visceral fat & --------- & $0.591(<0.001)$ & --------- & ns & $0.339(0.008)$ \\
\hline - Subcutaneous fat & ---------- & $-0.284(0.028)$ & --------- & --------- & Ns \\
\hline - Carotid IMT & ---------- & $0.285(0.027)$ & --------- & -------- & --------- \\
\hline
\end{tabular}

Values are expressed as R (p). "Body mass index; ${ }^{* *}$ Fasting plasma glucose. 
were correlated with BMI. Total cholesterol, triglycerides, VLDL cholesterol and systolic and diastolic blood pressure showed no correlation with either waist circumference or any ultrasound measurements, including carotid IMT. When the correlation of the parameters with one another measured by ultrasound was analyzed, preperitoneal circumference showed no correlation with any other measurements, while carotid IMT was correlated with visceral fat and preperitoneal circumference.

Multiple linear regression was performed to assess which of the measurements of central obesity and BMI were most closely related to the criteria for MS (Table 3). Visceral fat was independently associated with blood pressure and fasting glucose, while subcutaneous fat showed an independent association with HDL cholesterol. Preperitoneal circumference, BMI and waist circumference were not correlated with any of the dependent variables analyzed.

In assessing the independent contribution of components of MS, BMI and measurements of abdominal fat to carotid IMT, linear regression revealed that the levels of systolic and diastolic blood pressure and BMI were determinants of carotid IMT, regardless of the values of triglycerides, HDL, fasting blood sugar, and ultrasound measurements of abdominal obesity (Table 4).

\section{Discussion}

In this study, patients with MS had a higher mean age, waist circumference, BMI, fasting plasma glucose and triglycerides, and lower levels of HDL cholesterol than those without MS. Several studies corroborate these findings $[7,8,22,23]$. The blood pressure levels were not higher in the MS group, which can be explained by the greater use of antihypertensive drugs. In a cohort study conducted in Finland [24], there was likewise no statistical difference between the blood pressure levels of patients with and without MS but, unlike our study, there was no statistical significance between patients regarding the use of antihypertensive drugs.

The correlation between MS and greater values for carotid IMT has been repeatedly demonstrated [22-25], and the number of components of the syndrome has been related to an increase in carotid IMT [8].

All ultrasound measurements were significantly higher in the presence of the syndrome, except for subcutaneous fat, showing that intra-abdominal fat is the principal parameter related to the MS. Its value may be obtained directly, by measurement of visceral fat, or indirectly, by measurement of the preperitoneal circumference. The lack of association between subcutaneous fat and MS was observed in a study conducted with 290 subjects in China, in which the subcutaneous fat values were not significantly higher in patients with MS, and multivariate logistic regression did not demonstrate any independent association of fat with the syndrome [16].

When the relationship between the measurements of abdominal fat was evaluated, it was observed that abdominal obesity ultrasound measurements were correlated with the anthropometric measurements, waist circumference and BMI. These findings are in agreement with data from the literature $[26,27]$. Visceral fat was the one that presented a significant correlation with the greatest number of components of MS, with the exception of blood pressure and triglycerides levels. This, however, changed with linear regression, in which visceral fat was correlated with the blood pressure levels, maintaining the relationship with fasting plasma glucose, regardless of sex, age, BMI and the other measurements of abdominal fat. Furthermore, abdominal circumference, BMI, and preperitoneal circumference were not correlated with any component of the syndrome. These findings suggest that visceral fat is the measurement of central obesity that is best correlated with the risk factors analyzed. This superiority of visceral fat over subcutaneous fat was also

Table 3. Coefficients of multiple linear regression of the individual components of MS, using anthropometric data as independent variables, adjusted for gender and age (metabolic syndrome group).

\begin{tabular}{|c|c|c|c|c|c|c|}
\hline \multicolumn{7}{|c|}{ Independent variables } \\
\hline Dependent variables & BMI & Waist circumference & Subcutaneous fat & $\begin{array}{l}\text { Preperitoneal } \\
\text { circumference }\end{array}$ & Visceral fat & R-value ${ }^{2}$ \\
\hline $\mathrm{SBP}^{(1)}$ & $* *$ & $* *$ & $* *$ & $* *$ & $2.39(0.124)$ & 0.155 \\
\hline DBP & $* *$ & $* *$ & $* *$ & $* *$ & $2.28\left(0.018^{*}\right)$ & 0.113 \\
\hline $\mathrm{TG}^{(1)}$ & $* *$ & $* *$ & $* *$ & ** & $* *$ & 0.000 \\
\hline HDL & $* *$ & $* *$ & $-0.46\left(0.006^{*}\right)$ & $* *$ & $* *$ & 0.272 \\
\hline FPG & $* *$ & $* *$ & $* *$ & $* *$ & $10.58\left(0.012^{*}\right)$ & 0.106 \\
\hline
\end{tabular}

* Significant at $5.0 \% ;{ }^{* *}$ Variable excluded by the method of backward selection with $\mathrm{p}<0.15$. ${ }^{(1)}$ Remained the only constant in the model. Note: Values in brackets represent the probability of significance of each variable. 
Table 4. Coefficients of linear regression of carotid IMT in terms of ultrasound and anthropometry measurements and components of the SM, adjusted for sex and age (metabolic syndrome group).

\begin{tabular}{|c|c|}
\hline Independent variables & Dependent variable: carotid IMT \\
\hline SBP & $0.002(0.062)$ \\
\hline SPD & $-0.006\left(0.001^{*}\right)$ \\
\hline TG & ** \\
\hline HDL & $* *$ \\
\hline $\begin{array}{l}\text { Fasting plasma glucose } \\
\qquad(\mathrm{mg} / \mathrm{dl})\end{array}$ & $* *$ \\
\hline Waist circumference & ** \\
\hline BMI & $0.008\left(0.015^{*}\right)$ \\
\hline Preperitoneal circumference & ${ }^{* *}$ \\
\hline Visceral fat & ** \\
\hline Subcutaneous fat & ** \\
\hline R-value ${ }^{2}$ & $\mathrm{R}^{2}=0.458$ \\
\hline
\end{tabular}

*Significant at 5.0\%; ** Variable excluded by the method of backward selection with $\mathrm{p}<0.15$. Note: Values in brackets represent the probability of significance of each variable.

superiority of visceral fat over subcutaneous fat was also evaluated in a study conducted in Turkey, which found that visceral fat may play an important role in the physiopathology of MS [28]. A study with 177 volunteers in Spain showed that preperitoneal circumference was strongly correlated with all components of MS [29], whereas in our study there was no correlation with any of them. Moreover, the preperitoneal circumference was considered better than visceral fat. This difference between the results can be explained by the fact that, in the Spanish study, visceral fat was measured differently and was considered synonymous with preperitoneal fat.

On linear regression analysis, performed to assess the determinants of subclinical atherosclerosis, blood pressure and BMI showed a positive correlation with carotid IMT, regardless of sex, age, abdominal obesity ultrasound measurements, anthropometric parameters and components of MS. Therefore, in this study, general obesity was more correlated than central obesity with subclinical atherosclerosis. In the study by Fadini and colleagues, waist circumference and blood pressure were independently correlated with carotid IMT [30], while in the study by Kawamoto, age, male gender, systolic blood pressure, HDL, LDL, smoking, diabetes mellitus and MS showed an independent association with carotid IMT [9]. Scuteri, in a prospective study, found that age, male gender, LDL and fasting plasma glucose were independent factors associated with this measurement [7]. It may therefore be stated that the relationship between the components of MS and carotid IMT is still controversial, but factors such as age [16], blood pressure levels [31] and BMI [20] may be important determinants in several studies, including our own.

This study had a number of limitations. It did not determine a temporal relationship between obesity, MS and subclinical atherosclerosis. Furthermore, the population studied was relatively small and composed largely of women. Prospective studies with a larger number of participants of both genders are therefore required to confirm our data.

In conclusion, visceral fat was the measurement of abdominal fat that showed the best correlation with markers of MS, suggesting that it can be used as a useful parameter in assessing cardiovascular risk. Age, blood pressure and BMI were independently associated with subclinical atherosclerosis. The presence of MS was related to a higher carotid IMT, emphasizing that early detection and control of MS should be part of strategy to be employed in the prevention of CVD.

\section{Acknowledgements}

No competing financial interest exists. The authors have no potential conflicts of interest to be disclosed.

\section{REFERENCES}

[1] S. M. Grundy, H. B. Brewer Jr. and J. I. Cleeman, "Definition of Metabolic Syndrome. Report of the National Heart, Lung, and Blood Institute/American Heart Association Conference on Scientific Issues Related to Definition," Circulation, Vol. 109, No. 3, 2004, pp. 443-438. doi:10.1161/01.CIR.0000111245.75752.C6

[2] H. M. Lakka, D. E. Laaksonen, T. A. Lakka, L. K. Niskanem, et al., "The Metabolic Syndrome and Total and Cardiovascular Disease Mortality in Middle-Aged Men," Journal of American Medical Association, Vol. 288, No. 21, 2002, pp. 2709-2716. doi:10.1001/jama.288.21.2709

[3] H. Gang, Q. Qiao, J. Tuomilehto, B. Balkau, et al., "Prevalence of the Metabolic Syndrome and Its Relation to All Causes and Cardiovascular Mortality in Nondiabetic European Men and Women," Archives of Internal Medicine, Vol. 164, No. 10, 2004, pp. 1066-1076. doi:10.1001/archinte.164.10.1066

[4] S. Malik, N. Wong, S. S. Franklin, et al., "Impact of the Metabolic Syndrome on Mortality from Coronary Heart Disease, Cardiovascular Disease, and All Causes in United States Adults," Circulation, Vol. 110, No. 10, 2004, pp. 1245-1250. doi:10.1161/01.CIR.0000140677.20606.0E

[5] Y. He, B. Jiang, J. Wang, et al., "Prevalence of the Metabolic Syndrome and Its Relation to Cardiovascular Disease in an Elderly Chinese Population," Journal of the American College of Cardiology, Vol. 47, No. 8, 2005, pp. 1588-1594. doi:10.1016/j.jacc.2005.11.074

[6] P. Wilson, R. D'Agostino, H. Parise, et al., "Metabolic 
Syndrome as a Precursor of Cardioavascular Disease and Type 2 Diabetes Mellitus," Circulation, Vol. 112, No. 20, 2005, pp. 3066-3072. doi:10.1161/CIRCULATIONAHA.105.539528

[7] A. Scuteri, S. S. Najjar, D. C. Muller, R. Andres, et al., "Metabolic Syndrome Amplifies the Age-Associated Increases in Vascular Thickness and Stiffness," Journal of the American College of Cardiology, Vol. 43, No. 8, 2004, pp. 1388-1395. doi:10.1016/j.jacc.2003.10.061

[8] E. Bonora, S. Kiechl, J. Willeit, F. Oberhollenzer, et al., "Carotid Atherosclerosis and Coronary Heart Disease in the Metabolic Syndrome," Diabetes Care, Vol. 26, No. 4, 2003, pp. 1251-1257. doi:10.2337/diacare.26.4.1251

[9] R. Kawamoto, H. Tomita, Y. Oka, A. Kodama, et al., "Metabolic Syndrome Amplifies the LDL-Cholesterol Associated Increases in Carotid Atherosclerosis," Internal Medicine, Vol. 44, No. 12, 2005, pp. 1232-1238. doi:10.1056/NEJM199901073400103

[10] D. H. O’Leary, J. F. Polak, R. A. Kronmal, T. A. Manolio, et al., "Carotid-Artery Intima Media Thickness as a Risk Factor for Myocardial Infarction and Stroke in Older Adults," New England Journal of Medicine, Vol. 340, No. 1, 1999, pp. 14-22.

[11] W. S. Tzou, P. S. Douglas, S. R. Srinivasan, M. G. Bond, et al., "Increased Subclinical Atherosclerosis in Young Adults with Metabolic Syndrome," Journal of the American College of Cardiology, Vol. 46, No. 3, 2005, pp. 457-463. doi:10.1016/i.jacc.2005.04.046

[12] R. H. Y. Yu, S. C. Ho, S. S. Y. Ho, J. L. F. Woo, et al., "Association of General and Abdominal Obesities and Metabolic Syndrome with Subclinical Atherosclerosis in Asymptomatic Chinese Postmenopausal Women," Menopause, Vol. 15, No. 1, 2008, pp. 185-192.

[13] A. H. Kissebah, N. Vydelingum, R. Murray, et al., "Relation of Body Fat Distribution to Metabolic Complications of Obesity," The Journal of Clinical Endocrinology and Metabolism, Vol. 54, No. 2, 1982, pp. 254-260. doi:10.1210/jcem-54-2-254

[14] M. P. Reilly and D. J. Rader, "The Metabolic Syndrome: More than the Sum of Its Parts?" Circulation, Vol. 108, No. 13, 2003, pp. 1546-1551. doi:10.1161/01.CIR.0000088846.10655.E0

[15] D. J. Nieves , M. Cnop, B. Retzlaff, et al., "The Atherogenic Lipoprotein Profile Associated with Obesity and Insulin Resistance Is Largely Attributable to Intra-Abdominal Fat," Diabetes, Vol. 52, No. 1, 2003, pp. 172179. doi:10.2337/diabetes.52.1.172

[16] K. H. Liu, Y. L. Chan, W. B. Chan, J. C. N. Chan, et al., "Mesenteric Fat Thickness Is an Independent Determinant of Metabolic Syndrome and Identifies Subjects with Increased Carotid Intima-Media Thickness," Diabetes Care, Vol. 29, No. 2, 2006, pp. 379-384. doi:10.2337/diacare.29.02.06.dc05-1578

[17] S. R. Smith, J. C. Lovejoy, F. Greenway, et al., "Contributions of Total Body Fat, Abdominal Subcutaneous Adipose Tissue Compartments and Visceral Adipose Tissue to the Metabolic Complications of Obesity," Metabolism, Vol. 50, No. 4, 2001, pp. 425-435. doi:10.1053/meta.2001.21693
[18] K. H. Liu, Y. L. Chan, J. C. N. Chan and W. B. Chan, "Association of Carotid Intima-Media Thickness with Mesenteric, Preperitoneal and Subcutaneous Fat Thickness," Atherosclerosis, Vol. 179, No. 2, 2005, pp. 299304. doi:10.1016/j.atherosclerosis.2004.10.038

[19] F. Armellini, M. Zamboni, L. Rigo, T. Todesco, et al., "The Contribution of Sonography to the Measurement of Intra-Abdominal Fat," Journal of Clinical Ultrasound, Vol. 18, No. 7, 1990, pp. 563-567. doi:10.1002/jcu.1870180707

[20] E. Meriño-Ibarra, M. Artieda, A. Cenarro, J. Goicoechea, et al., "Ultrasonography for the Evaluation of Visceral Fat and the Metabolic Syndrome," Metabolism Clinical and Experimental, Vol. 54, No. 9, 2005, pp. 1230-1235. doi:10.1016/j.metabol.2005.04.009

[21] S. M. Grundy, J. I. Cleeman, S. R. Daniels, K. A. Donato, et al., "Diagnosis and Management of the Metabolic Syndrome: An American Heart Association/National Heart, Lung, and Blood Institute Scientific Statement," Circulation, Vol. 112, No. 17, 2005, pp. 2735-2752. doi:10.1161/CIRCULATIONAHA.105.169404

[22] R. A. Dehnavi, E. D. Beishuizen, M. A. Van de Ree, S. Le Cessie, et al., "The Impact of Metabolic Syndrome and CRP on Vascular Phenotype in Type 2 Diabetes Mellitus," European Journal of Internal Medicine, Vol. 19 No. 2, 2008, pp. 115-121. doi:10.1016/j.ejim.2007.06.011

[23] B. Iglseder, P. Cip, L. Malaimare, G. Ladurner, et al., "The Metabolic Syndrome Is a Stronger Risk Factor for Early Carotid Atherosclerosis in Women than in Men," Stroke, Vol. 36, No. 6, 2005, pp. 1212-1217. doi:10.1161/01.STR.0000166196.31227.91

[24] M. Hassinen, P. Komulainen, T. A. Lakka, et al., "Metabolic Syndrome and the Progression of Carotid Intima-Media Thickness in Elderly Women," Archives of Internal Medicine, Vol. 166, No. 4, 2006, pp. 444-449.

[25] J. P. Empana, M. Zureik, J. Gariepy, D. Courbon, et al., "The Metabolic Syndrome and the Carotid Artery Structure in Noninstitutionalized Elderly Subjects," Stroke, Vol. 38, No. 3, 2007, pp. 893-899. doi:10.1161/01.STR.0000257983.62530.75

[26] R. B. Radominski, D. P. Vezozzo, G. G. Cerri and A. Halpern, "O Uso da Ultra-Sonografia na Avaliação da Distribuição de Gordura Abdominal," Arquivos Brasile Endocrinol Metabolism, Vol. 44, No. 1, 2000, pp. 5-12. doi:10.1590/S0004-27302000000100003

[27] N. Sabir, Y. Sermez, S. Kazil and M. Zencir, "Correlation of Abdominal Fat Accumulation and Liver Steatosis: Importance of Ultrasonographic and Anthropometric Measurements," European Journal of Ultrasound, Vol. 14, No. 2-3, 2001, pp. 121-128. doi:10.1016/S0929-8266(01)00153-7

[28] S. Guldiken, N. Tuncbilek, O. O. Okten, E. Arikan, et al., "Visceral Fat Thickness Determined Using Ultrasonography Is Associated with Anthropometric and Clinical Parameters of Metabolic Syndrome," International Journal of Clinical Practice, Vol. 60, No. 12, 2006, pp. 15761581. doi:10.1111/j.1742-1241.2005.00803.x

[29] E. Meriño-Ibarra, M. Artieda, A. Cenarro, J. Goicoechea, 
et al., "Ultrasonography for the Evaluation of Visceral Fat and the Metabolic Syndrome," Metabolism Clinical and Experimental, Vol. 54, No. 9, 2005, pp. 1230-1235. doi:10.1016/j.metabol.2005.04.009

[30] G. P. Fadini, A. Coracina, S. Inchiostro, A. Tiengo, et al., "A Stepwise Approach to Assess the Impact of Clustering Cardiometabolic Risk Factors on Carotid Intima-Media Thickness: The Metabolic Syndrome No-More-Than-Additive," European Journal of Cardiovascular Prevention and Rehabilitation, Vol. 15, No. 2, 2008, pp. 190-196. doi:10.1097/HJR.0b013e3282f17bc3

[31] N. Mattsson, T. Ronnemaa, M. Juonala, J. S. A. Viikari, et al., "Arterial Structure and Function in Young Adults with the Metabolic Syndrome: The Cardiovascular Risk in Young Finns Study," European Heart Journal, Vol. 29, No. 6, 2008, pp. 784-791. doi:10.1093/eurheartj/ehm576 